\title{
Measurement of blood pressure
}

\author{
Wilbert S. Aronow \\ Cardiology Division, Department of Medicine, Westchester Medical Center and New York Medical College, Valhalla, NY, USA \\ Correspondence to: Wilbert S. Aronow, MD, FACC, FAHA. Professor of Medicine, Cardiology Division, Westchester Medical Center and New York \\ Medical College, Macy Pavilion, Room 138, Valhalla, NY 10595, USA. Email: wsaronow@aol.com.
}

Submitted Dec 11, 2016. Accepted for publication Dec 13, 2016.

doi: 10.21037/atm.2017.01.09

View this article at: http://dx.doi.org/10.21037/atm.2017.01.09

Hypertension is a major risk factor for cardiovascular events and mortality (1-4). Hypertension occurs in 69\% of individuals with first myocardial infarction (5), $77 \%$ of individuals with first stroke (5), $74 \%$ of individuals with heart failure (5), and $60 \%$ of individuals with peripheral arterial disease (6). Hypertension has been diagnosed if the systolic blood pressure is $140 \mathrm{mmHg}$ or higher or if the diastolic blood pressure is $90 \mathrm{mmHg}$ or higher (1-4). However, on the basis of data from the Systolic Blood Pressure Intervention Trial (SPRINT) $(7,8)$ and a meta-analysis of prospective studies showing the impact of baseline prehypertension on cardiovascular events and all-cause mortality in the general population (9), this author considers hypertension to be either a systolic blood pressure of $130 \mathrm{mmHg}$ or higher or a diastolic blood pressure of $80 \mathrm{mmHg}$ or higher.

Pseudohypertension is a falsely increased systolic blood pressure caused by markedly atherosclerotic arteries which do not collapse during inflation of the blood pressure cuff $(2,10)$. Pseudohypertension should be suspected in older persons with refractory hypertension, no target organ damage or cardiovascular disease, and symptoms of overmedication (2). Diagnosis of pseudohypertension should be confirmed by direct intra-arterial measurement of blood pressure (11).

White coat hypertension is diagnosed if a patient not receiving antihypertensive medication has a persistently high office blood pressure with a normal; ambulatory blood pressure or home blood pressure (1-3,12). Masked hypertension is diagnosed if the patient has a normal office blood pressure measurement but increased ambulatory blood pressure monitoring or home blood pressure measurements that are consistently increased (13).

Measurement of blood pressure is very important in the diagnosis and treatment of hypertension. This editorial will discuss the appropriate measurement of blood pressure.

Hypertension is diagnosed if the blood pressure is elevated on at least three different blood pressure measurements taken on two or more office visits $(1,2)$. The blood pressure should be taken after the patient is sitting comfortably for at least 5 minutes, with the back supported, feet on the floor, arm supported in the horizontal position on a desk or table, with the middle of the blood pressure cuff on the patient's upper arm at the level of the right atrium (the midpoint of the sternum) $(2,14)$. The correct blood pressure cuff size should be used so that the bladder encircles at least $80 \%$ of the upper arm circumference (2). The blood pressure device should be validated periodically. If the blood pressure is being taken with a mercury sphygmomanometer, the cuff pressure should be deflated $2 \mathrm{mmHg}$ per second with the systolic blood pressure recorded at the onset of the first Korotkoff sound and the diastolic blood pressure recorded when all Korotkoff sounds disappear. For manual determination of blood pressure, estimate the systolic blood pressure when the radial pulse is obliterated and inflate the cuff 20 to $30 \mathrm{mmHg}$ above this level for an auscultatory measurement of the blood pressure.

The patient must avoid smoking, drinking a caffeine beverage, and exercising for at least 30 minutes before the blood pressure is measured. The patient should empty his or her urinary bladder before the blood pressure is measured. Neither the patient nor the person measuring the blood pressure should talk during the procedure. All clothing covering the location of cuff placement should be removed.

The blood pressure also should be measured with the person standing for 1 to 3 minutes to evaluate for postural hypotension or hypertension $(2,15,16)$. Older patients should also be evaluated for postprandial hypotension, 
which is especially common in frail older patients taking multiple antihypertensive and psychotropic drugs $(2,17)$. During the initial blood pressure visit, the blood pressure should be measured in both arms with the arm with the highest blood pressure used for future monitoring of the blood pressure $(2,18)$.

Measurement of blood pressure by use of a mercury sphygmomanometer has given way to use of oscillometric devices which use a sensor to detect oscillations in pulsatile blood volume during cuff inflation and deflation. Blood pressure is indirectly calculated from maximum amplitude algorithms using population-based data. Only automated devices with a validated measurement protocol should be used. The SPRINT trial measured blood pressure during office visits with the patient sitting in a quiet room after 5 minutes of quiet rest with the use of an automated blood pressure measurement system (Model 907, Omron Healthcare) $(7,8)$. No other person was in the room during blood pressure measurement to avoid the white coat effect. Dose adjustment of medications was based on a mean of three blood pressure measurements. This method of blood pressure measurement is the most accurate.

Self-monitoring of blood pressure at home is very helpful in the diagnosis and management of hypertension $(2,19,20)$. At 1-year follow-up of 450 patients with hypertension at high risk of cardiovascular disease, compared with a control group, self-monitoring of blood pressure with self-titration of antihypertensive medication reduced the blood pressure 8.8/3.1 mmHg (19).

Ambulatory blood pressure monitoring is a better predictor of cardiovascular risk than office blood pressure measurements (2,21-23). A meta-analysis of 7,030 persons in four populations showed at a median of 9.5 years of follow-up that 10 to 20 hours of daytime ambulatory blood pressure monitoring predicted cardiovascular events better than conventional blood pressure monitoring (22). Cardiovascular risk increased from a normal blood pressure over white coat and masked hypertension to sustained hypertension (22). A meta-analysis of nine cohorts including 13,844 patients with hypertension showed that 9-time systolic blood pressure independently predicted cardiovascular events better than clinic systolic blood pressure and daytime systolic blood pressure (23).

The 2016 Canadian Hypertension Education Program Guideline from Hypertension Canada recommends the use of unattended automated office blood pressure measurements with a 5 -minute rest period as performed in the SPRINT trial $(7,8)$ in addition to home blood pressure measurement and ambulatory blood pressure measurement $(24,25)$. This author concurs with this recommendation.

\section{Acknowledgements}

None.

\section{Footnote}

Conflicts of Interest: The author has no conflicts of interest to declare.

\section{References}

1. Chobanian AV, Bakris GL, Black HR, et al. The Seventh Report of the Joint National Committee on Prevention, Detection, Evaluation, and Treatment of High Blood Pressure: the JNC 7 report. JAMA 2003;289:2560-72.

2. Aronow WS, Fleg JL, Pepine CJ, et al. ACCF/AHA 2011 expert consensus document on hypertension in the elderly: a report of the American College of Cardiology Foundation Task Force on Clinical Expert Consensus documents developed in collaboration with the American Academy of Neurology, American Geriatrics Society, American Society for Preventive Cardiology, American Society of Hypertension, American Society of Nephrology, Association of Black Cardiologists, and European Society of Hypertension. J Am Coll Cardiol 2011;57:2037-114.

3. Mancia G, Fagard R, Narkiewicz K, et al. 2013 ESH/ESC guidelines for the management of arterial hypertension: the Task Force for the Management of Arterial Hypertension of the European Society of Hypertension (ESH) and of the European Society of Cardiology (ESC). Eur Heart J 2013;34:2159-219.

4. Rosendorff C, Lackland DT, Allison M, et al. Treatment of Hypertension in Patients With Coronary Artery Disease: A Scientific Statement from the American Heart Association, American College of Cardiology, and American Society of Hypertension. J Am Coll Cardiol 2015;65:1998-2038.

5. Lloyd-Jones D, Adams R, Carnethon M, et al. Heart disease and stroke statistics--2009 update: a report from the American Heart Association Statistics Committee and Stroke Statistics Subcommittee. Circulation 2009; 119:480-6.

6. Aronow WS, Ahmed MI, Ekundayo OJ, et al. A propensity-matched study of the association of peripheral arterial disease with cardiovascular outcomes 
in community-dwelling older adults. Am J Cardiol 2009;103:130-5.

7. SPRINT Research Group, Wright JT Jr, Williamson JD, et al. A Randomized Trial of Intensive versus Standard Blood-Pressure Control. N Engl J Med 2015;373:2103-16.

8. Williamson JD, Supiano MA, Applegate WB, et al. Intensive vs Standard Blood Pressure Control and Cardiovascular Disease Outcomes in Adults Aged $\geq 75$ Years: A Randomized Clinical Trial. JAMA 2016;315:2673-82.

9. Wang $\mathrm{S}, \mathrm{Wu} \mathrm{H}$, Zhang Q, et al. Impact of baseline prehypertension on cardiovascular events and all-cause mortality in the general population: a meta-analysis of prospective cohort studies. Int J Cardiol 2013;168:4857-60.

10. Zweifler AJ, Shahab ST. Pseudohypertension: a new assessment. J Hypertens 1993;11:1-6.

11. Spence JD. Pseudo-hypertension in the elderly: still hazy, after all these years. J Hum Hypertens 1997;11:621-3.

12. Parati G, Stergiou GS, Asmar R, et al. European Society of Hypertension practice guidelines for home blood pressure monitoring. J Hum Hypertens 2010;24:779-85.

13. Banegas JR, Ruilope LM, de la Sierra A, et al. High prevalence of masked uncontrolled hypertension in people with treated hypertension. Eur Heart J 2014;35:3304-12.

14. Weir MR. In the clinic: hypertension. Ann Intern Med 2014;161:ITC1-15; quiz ITC16.

15. Aronow WS, Lee NH, Sales FF, et al. Prevalence of postural hypotension in elderly patients in a long-term health care facility. Am J Cardiol 1988;62:336.

16. Aronow WS. Orthostatic Hypotension in Diabetics in the ACCORD (Action to Control Cardiovascular Risk in Diabetes) Blood Pressure Trial. Hypertension 2016;68:851-2.

17. Aronow WS, Ahn C. Postprandial hypotension in 499 elderly persons in a long-term health care facility. J Am Geriatr Soc 1994;42:930-2.

Cite this article as: Aronow WS. Measurement of blood pressure. Ann Transl Med 2017;5(3):49. doi: 10.21037/ atm.2017.01.09
18. Mendelson G, Nassimiha D, Aronow WS. Simultaneous measurements of blood pressures in right and left brachial arteries. Cardiol Rev 2004;12:276-8.

19. McManus RJ, Mant J, Haque MS, et al. Effect of selfmonitoring and medication self-titration on systolic blood pressure in hypertensive patients at high risk of cardiovascular disease: the TASMIN-SR randomized clinical trial. JAMA 2014;312:799-808.

20. Agarwal R, Bills JE, Hecht TJ, et al. Role of home blood pressure monitoring in overcoming therapeutic inertia and improving hypertension control: a systematic review and meta-analysis. Hypertension 2011;57:29-38.

21. Staessen JA, Thijs L, Fagard R, et al. Predicting cardiovascular risk using conventional vs ambulatory blood pressure in older patients with systolic hypertension. Systolic Hypertension in Europe Trial Investigators. JAMA 1999;282:539-46.

22. Hansen TW, Kikuya M, Thijs L, et al. Prognostic superiority of daytime ambulatory over conventional blood pressure in four populations: a meta-analysis of 7,030 individuals. J Hypertens 2007;25:1554-64.

23. ABC-H Investigators, Roush GC, Fagard RH, et al. Prognostic impact from clinic, daytime, and nighttime systolic blood pressure in nine cohorts of 13,844 patients with hypertension. J Hypertens 2014;32:2332-40; discussion 2340.

24. Padwal R, Rabi DM, Schiffrin EL. Recommendations for Intensive Blood Pressure Lowering in High-Risk Patients, the Canadian Viewpoint. Hypertension 2016;68:3-5.

25. Leung AA, Nerenberg K, Daskalopoulou SS, et al. Hypertension Canada's 2016 Canadian Hypertension Education Program Guidelines for Blood Pressure Measurement, Diagnosis, Assessment of Risk, Prevention, and Treatment of Hypertension. Can J Cardiol 2016;32:569-88. 